\title{
Microinjertos en sello de heridas crónicas recalcitrantes
}

\author{
Laura Pérez Jerónimo ${ }^{(1)}$, Elena Conde Montero ${ }^{(1)}$, Alicia Peral Vázquez ${ }^{(1)}$, Soledad Guisado Muñoz ${ }^{(1)}, M^{a}$ Paz Villar \\ Espantoso (1), Ma Isabel Izquierdo Nazar (1) \\ (1) Centro de especialidades Vicente Soldevilla \\ Hospital Universitario Infanta Leonor
}

\section{Correspondencia:}

Laura Pérez Jerónimo

laurpi@gmail.com

\section{RESUMEN}

Las heridas crónicas disminuyen la calidad de vida de los pacientes que las padecen, incidiendo significativamente en su estado de salud y agravando su pronóstico general. La elevada incidencia y prevalencia de las úlceras en pierna, así como su alta cronicidad y recidiva, suponen un impacto psico-socio-sanitario elevado, con un alto gasto sanitario y una importante carga personal, familiar y social asociadas. La cicatrización de estos defectos representan un reto terapéutico para el personal sanitario, tanto en el primer eslabón asistencial como en hospitales.

La cobertura de las heridas crónicas con microinjertos cutáneos en sello es una técnica eficiente, con muy buenos resultados ${ }^{3}$. Disminuye los tiempos de cicatrización y los costes del proceso, especialmente si se realiza de manera ambulatoria. Es una técnica sencilla, beneficiosa per se para la epitelización por la cantidad de factores de crecimiento, células y otras moléculas que de los pequeños fragmentos de piel, se liberan sobre el lecho de las heridas. Otro de los beneficios que podemos atribuir a los microinjertos autólogos en sello es su efecto analgésico desde las primeras horas de su colocación.

\section{INTRODUCCIÓN}

La cicatrización de heridas sigue siendo un reto para el personal sanitario en el siglo XXI.

Las úlceras vasculares presentan una prevalencia que oscila entre $0.10 \%-0.30 \%$, con una incidencia entre 3 y 5 nuevos casos/1000/año. Estas cifras se duplican en segmentos de población mayores de 65 años. Destaca su alta cronicidad y recidiva. El 40-50\% permanecen activas entre 6 meses y 1 año y un $10 \%$ alcanzan los 5 años de evolución(1). También es destacable que las úlceras de pie diabético son la primera causa de amputación no traumática en el mundo(1).

El cierre de las heridas crónicas supone una alta tasa en cuidados de enfermería, sobre todo en heridas de difícil cicatrización, debido a la falta de respuesta a los tratamientos aplicados y a la elevada prevalencia del proceso(2).

Todas las heridas crónicas, y en especial las recalcitrantes, disminuyen la calidad de vida de los pacientes que las padecen. No sólo por el dolor o la limitación funcional que de ellas se derivan, sino también por la repercusión significativa que tienen sobre el estado de salud del paciente, agravando su pronóstico general(3) El impacto psico-socio-sanitario de las heridas crónicas es elevado, con un alto gasto sanitario y una importante carga personal, familiar y social asociadas (1).

La cobertura de las heridas crónicas con injertos es una técnica muy utilizada en otros países con muy buenos resultados $(2,4)$.

En la consulta de heridas del centro de especialidades Vicente Soldevilla, dependiente del equipo de dermatología del Hospital Universitario Infanta Leonor, se utilizan los injertos autólogos en sello, de piel parcial y corte fino.

El objetivo de este monográfico es hacer una descripción de la técnica y sus principales indicaciones.

¿Qué son los injertos autólogos en sello?

Los microinjertos autólogos en sello (MAS) son injertos de espesor parcial, fragmentos dermo-epidérmicos más o menos circulares u ovalados, que se obtiene, sin profundizar más allá de la dermis papilar, tras anestesiar localmente la zona donante, habitualmente el muslo (5).

Los tipos de injertos que se pueden utilizar para cubrir heridas, los podemos clasificar, en función de su origen:

- Autoinjerto o injerto autólogo: piel obtenida de una zona donante del propio paciente.

- Aloinjerto o injerto heterólogo: piel obtenida de otra persona.

- Xenoinjerto o heteroinjerto: piel procedente de otras especies, como el cerdo.

- Sustitutos cutáneos sintéticos: manufacturados en un laboratorio o industria. Pueden ser epidérmicos (cultivos de queratinocitos), dérmicos o dermoepidérmicos (piel artificial)

Sólo se consideran permanentes los autoinjertos. El resto, ya sea por su composición (degradables por el huésped) o por su origen (rechazados por la respuesta inmune del huésped), sólo aportan una cobertura temporal, durante unas semanas.

En función de su espesor, se clasifican en (4) 
- Injerto de piel total: incluye dermis y epidermis. La incisión se realizar hasta el tejido subcutáneo y se obtiene una cuña de piel. Los bordes del defecto resultante en la zona dadora se aproximan mediante sutura directa.

- Injerto de piel parcial: su grosor está entre 0.2-0.4 mm. El plano de corte se encuentra por encima de los folículos pilosos que, al mantenerse en la zona dadora, permiten que ésta cierre por segunda intención. Se dividen en finos y gruesos.

- Injerto epidérmico: formado únicamente por epidermis.

¿Qué técnica utilizamos habitualmente para obtener injertos autólogos de piel parcial?

Es una técnica muy sencilla que requiere un instrumental quirúrgico básico, unas pinzas y tijeras serían suficientes. En nuestra consulta se utiliza una cureta dermatológica o un sacabocados para obtener los MAS.

El procedimiento se realiza de manera estéril, con una pequeña mesa quirúrgica para el material, dos campos estériles, uno en la zona donante y otro en la receptora, y un equipo formado por tres personas. En nuestro caso, un dermatólogo y dos enfermeras, siendo el dermatólogo el encargado de extraer los fragmentos de piel, y la enfermera se encarga de emplazarlos en el lecho de la herida. La tercera persona haría las funciones de enfermera circulante.

En primer lugar se selecciona la zona donante, que debe estar libre de cicatrices, telangiectasias u otros defectos, generalmente de la cara anterior del muslo. Tras la infiltración del anestésico, lidocaína al 1\%, diluida al 50\% con suero fisiológico, se marca la superficie cutánea con el sacabocados y se extraen los fragmentos de piel con ayuda de las pinzas y el bisturí (Imagen № 1). A la vez que se obtienen, se van colocando sobre la herida a modo de tesela de mosaico, con una separación que oscila entre los 2 y los $5 \mathrm{~mm}$, dependiendo de la extensión de la herida a cubrir y de la calidad del lecho a injertar.

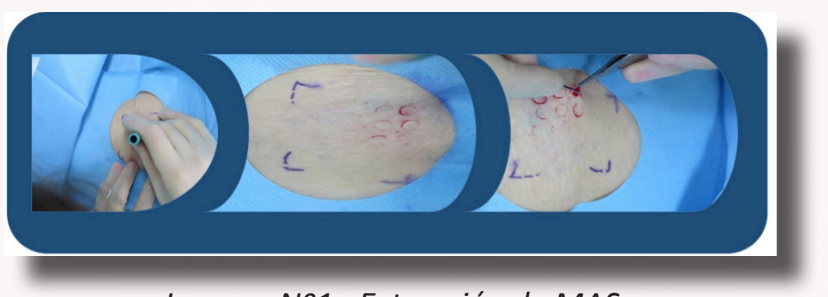

Imagen №1: Extracción de MAS

Posteriormente, la enfermera se encarga de cubrir la lesión injertada con una interfase no adherente como apósito primario y un apósito absorbente como secundario, que se selecciona en función del exudado previo. Se presta gran atención a la protección de la piel perilesional, puesto que durante los primeros días posteriores al procedimiento, al establecerse la angiogénesis, se produce un incremento del exudado.

La zona donante se cubre con una lámina de alginato, que se retirará el mismo día que se levante por primera vez la cura de la zona injertada. Dependiendo de la evolución de la herida quirúrgica, se dejarán al aire o se volverá a colocar algún apósito absorbente.

Para un adecuado prendimiento del injerto, es esencial la presión local e inmovilización del miembro con reposo para evitar el desplazamiento de los fragmentos cutáneos hasta la neoangiogénesis. Para ello, se realiza un vendaje de sujeción o compresivo en función de la etiología de la lesión o del ITB de la extremidad inferior, e incluso una descarga o un dispositivo portátil de terapia de presión negativa (TPN), si la patología o la localización lo requiere.

La primera cura se realiza entre 3 y 7 días después de la intervención, dependiendo de la extensión, localización y el exudado previo.

Las heridas de la zona donante cicatrizan por segunda intención.

El riesgo de sangrado y sobreinfección de la zona de la que se obtienen los injertos es mínimo.

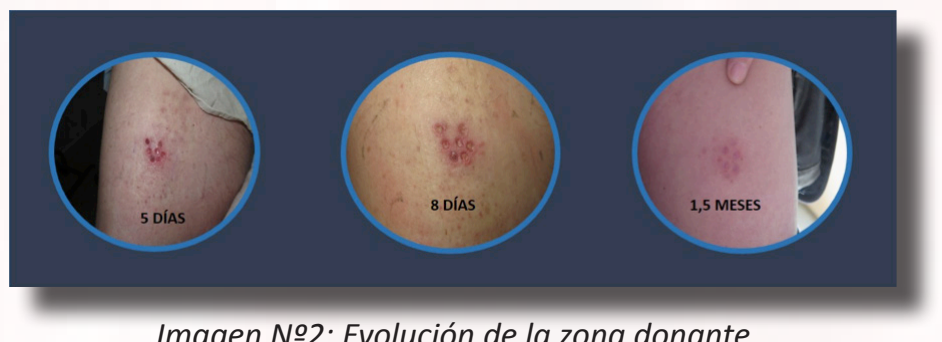

Imagen №2: Evolución de la zona donante

La técnica es muy eficiente puesto que disminuye los tiempos y los costes de cicatrización, especialmente si se realiza de manera ambulatoria, como es nuestro caso, ya que se evita el ingreso del paciente y la utilización de quirófano.

La enfermera juega un papel fundamental en todo el proceso, desde la preparación del lecho, la educación sanitaria, la disposición de los MAS, la cobertura de la lesión injertada y la planificación y realización de las sucesivas curas. Es función de la enfermera transmitir y asegurarse de que el paciente ha entendido las recomendaciones de deambulación y antiedema que se le entregan. Estas pautas, consistentes en reposo con piernas ligeramente elevadas (posición antiedema) y deambulación progresiva desde el tercer día, influyen directamente en un éxito mayor de la técnica.

Otro de los beneficios de esta técnica es el efecto analgésico que posee. Diferentes estudios así lo demuestran (4)(5)(7) y nuestra experiencia así lo constata. Hemos realizado un estudio con 29 pacientes, que actualmente estamos ampliando, tratados con MAS, donde se midió la intensidad del dolor con una escala visual analógica (EVA) y se registró el dolor en el momento previo al procedimiento (to) y en las tres primeras visitas de seguimiento (t1, t2 y t3). La reducción del dolor tras la aplicación de los microinjertos cutáneos fue clínica y estadísticamente significativa.

El estudio fue presentado en el congreso de AEEVH de 2017 bajo el título, Reducción del dolor en heridas crónicas tratadas con microinjertos cutáneos. Corroboramos el poder analgésico de la técnica, cualidad que la hace muy útil en la úlcera isquémicohipertensiva de Martorell, una entidad muy dolorosa. 


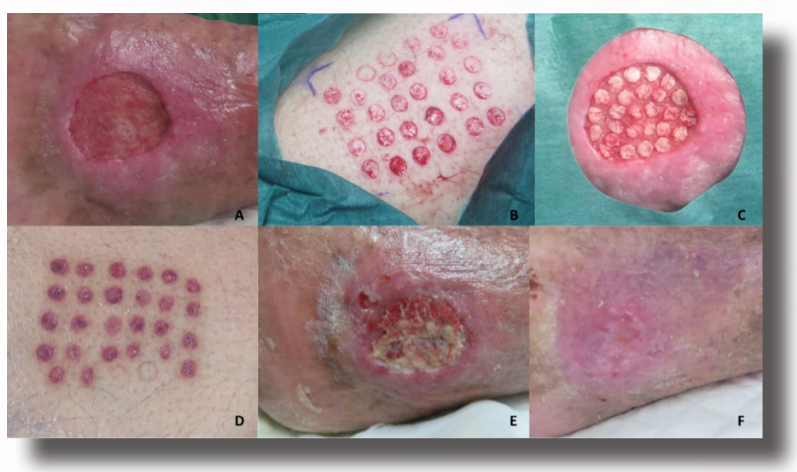

Imagen №3: Epitelización completa en 6 semanas

¿Cuándo es injertable un lecho?

La preparación del lecho es, sin lugar a dudas, la parte más complicada del proceso. Requiere un trabajo multidisciplinar y un abordaje holístico del paciente. Hay que comenzar por realizar una buena historia clínica, valorando tanto los factores generales del paciente (edad, comorbilidades, medicación o estado nutricional) como los factores locales (etiología, extensión, localización, tiempo de evolución, tejido presente en el lecho), puesto que son variables esenciales a tener en cuenta para establecer un tratamiento convencional que nos lleve a obtener el mejor lecho.

Cuando contamos con un buen tejido de granulación, hay control del exudado y de la carga bacteriana, y la herida es superficial, la técnica tiene mayor probabilidad de éxito. Sin embargo, en la práctica diaria conseguir este lecho ideal no siempre es sencillo o alcanzable a corto plazo, por lo que, en muchas ocasiones, injertamos lechos de características subóptimas. La experiencia nos dice que, aunque no prendan todas las piezas, se produce una aceleración del proceso de cicatrización y una disminución del dolor, un factor extremadamente limitante para el paciente.

En nuestra consulta consideramos esencial la educación sanitaria del paciente y su familia, ya que es la forma de asegurar la adherencia a la compresión terapéutica. Somos especialmente insistentes en las medidas anti-edema y en la pro-actividad del paciente, sin olvidar el abandono de los hábitos poco saludables relacionados con sus patologías.

\section{¿Qué tipo de heridas se pueden injertar?}

No existe limitación de la técnica en cuanto a etiología de la lesión a excepción del pioderma gangrenoso. Esta limitación no es por la colocación de los MAS en la herida, sino por el riesgo de que se produzca un fenómeno de patergia en la zona dadora. El fenómeno de patergia consiste en la aparición de lesiones nuevas de pioderma gangrenoso tras traumatismo, en este caso quirúrgico.

El resto de las heridas que no requieran una intervención previa, como puede ser una revascularización o una resección quirúrgica, son todas microinjertables.

¿Se pueden combinar con otras técnicas?

Antes de realizar microinjertos podemos tratar las heridas de los paciente con terapias convencionales o avanzadas, como oxigeno hiperbárico, terapia de presión negativa, sustitutos cutáneos.

Una vez realizados los MAS, y durante unas semanas, lo más recomendable es no modificar el microambiente creado por los injertos. En este momento, sólo recomendamos control y limpieza de la piel perilesional.

El uso combinado de los MÁS y TPN, tiene gran interés, ya que la aplicación de presión negativa promueve la formación de tejido de granulación, con reducción del exudado y de la carga bacteriana y, por tanto, facilita el prendimiento de los injertos. Además, la aplicación de TPN sobre la zona receptora después de la técnica puede mejorar el porcentaje de prendimiento, ya que la TPN reduce el exudado y mejora el sellado del injerto, con la consiguiente disminución del cizallamiento y una menor aparición de seromas y hematomas. Por otro lado, se ha propuesto que el estiramiento mecánico que produce la presión negativa puede estimular las vías de señalización que promueven la mitosis de los queratinocitos y activar la neoangiogénesis al aumentar el flujo microcirculatorio en el lecho y los bordes de la herida (8-9).

El uso combinado de MAS y TPN es muy recomendable en lechos muy senescentes, heridas de personas mayores con piel fina (dermatoporosis), localizaciones anatómicas complicadas, úlceras por presión y pie diabético.

\section{¿Qué beneficios tiene?}

La técnica es beneficiosa per se para la cicatrización de heridas, puesto que se liberan gran cantidad de factores de crecimiento epidérmicos y otras moléculas y células que acortan mucho los tiempos de epitelización (Imagen №3) y producen también una disminución del dolor desde las primeras horas, reduciendo por estos motivos los costes del proceso (5-7).

Dado que la técnica se realiza con material económico, es sencilla y se puede realizar de manera ambulatoria, se puede considerar un procedimiento altamente eficiente.

\section{¿Cuáles son las limitaciones de la técnica?}

Para aumentar la eficiencia del procedimiento, se necesita práctica y trabajo en equipo. Sin duda, el conocimiento anatómico de la piel y la experiencia son claves para realizar el procedimiento de manera sistemática y rápida.

Por otro lado, cuando la superficie a injertar es extensa, la larga duración del procedimiento en posturas no siempre ergonómicas, puede impactar en la tolerancia del paciente.

Finalmente, a veces hay que repetir el procedimiento, dado que el lecho que se trata no siempre es óptimo y puede precisar varias sesiones de MAS para conseguir un prendimiento y cierre completos. 


\section{BIBLIOGRAFÍA}

1. Asociación Española de Enfermería Vascular y Heridas. Guía de práctica clínica: Consenso sobre úlceras vasculares y pie diabético. Tercera edición. Madrid: AEEVH, 2017. Disponible en :

https://www.aeev.net/pdf/Guiade-Practica-Clinica-web.pdf

2. Pérez Vega Francisco J, Gutiérrez Vázquez MT, Lorenzo Peñuelas JR, Domínguez Bermúdez JF, Armario Hita JC, Castro Maqueda G. Alternativa al cierre de heridas crónicas mediante injertos de Reverdin y factores de crecimiento en cirugía menor ambulatoria. Gerokomos [Internet]. 2015 [citado 2017 Oct 26]; 26 (1): 34-39. Disponible en: http://dx.doi.org/10.4321/S1134-928X2015000100008.

3. Servicio Madrileño de Salud. Recomendaciones para el tratamiento local de las úlceras cutáneas crónicas de la Comunidad de Madrid. Madrid: Comunidad de Madrid. Consejería de Sanidad; 2010.

4. Revol M, Servant JM. Greffes cutanées. In: Encycl Med Chir (EMC).Techniques chirurgicales. Chirurgie plastique reconstructive et esthétique. Issy-les-Moulineaux: ElsevierMasson; 2010: 45-70.

5. Fourgeaud C, Mouloise G, Michon-Pasturel U, Bonhomme S, Lazareth I, Meaume $S$ et al. Interest of punch skin grafting for the treatment of painful ulcers. J Mal Vasc. 2016; 41:323-328.
6. Dagregorio G, Guillet G. A retrospective review of 20 hypertensive leg ulcers treated with mesh skin grafts. J Eur Acad Dermatol Venereol 2006; 20:166.

7. Nordström A, Hansson C. Punch-grafting to enhance healing and to reduce pain in complicated leg and foot ulcers. Acta Derm Venereol. 2008; 88:389-389.

8. Llanos S, Danilla S, Barraza C, Armijo E, Pineros JL, Quintas M, et al. Effectiveness of negative pressure closure in the integration of split thickness skin grafts. A randomized, double-masked, controlled trial. Ann Surg 2006; 244(5):700-705.

9. Azzopardi EA, Boyce DE, Dickson WA, Azzopardi E, Laing JH, Whitaker IS, Shokrollahi K. Application of topical negative pressure (vacuum-assisted closure) to split-thickness skin grafts: a structured evidence-based review. Ann Plast Surg. 2013; 70(1):23-29. 